\title{
Criação e Transporte de Ninfas de Ephemeroptera (Insecta) em Campo
}

\author{
Rafael Boldrini ${ }^{\circledR}$ \& Paulo Vilela Cruz ${ }^{1,2}$
}

1. Instituto Nacional de Pesquisas da Amazonia, e-mail: rafaelboldrini@yahoo.com.br (Autor para correspondência ${ }^{\bowtie}$ ). 2. Instituto Federal de Educação, Ciência e Tecnologia do Amazonas - IFAM, e-mail: pvilelacruz@gmail.com.

\section{EntomoBrasilis 6(2): 168-17o (2013)}

Resumo. Muitas espécies de Ephemeroptera são conhecidas somente em um estágio, normalmente adulto ou ninfa. Nesse estudo é proposto uma metodologia para transporte e criação de ninfas em campo.

Palavras-chave: Inseto aquático; Ephemeroptera; macroinvertebrado.

\section{Rearing and Transport of Mayfly Nymphs in the Field}

Abstract. Many species of Ephemeroptera are known in only one phase, adult or nymph. In this study, we propose a methodology for transport and rearing nymphs in the field.

Keywords: Aquatic insect; Ephemeroptera; macroinvertebrate.

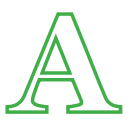

ordem Ephemeroptera (Insecta) é considerada um grupo oligodiverso, representada atualmente por aproximadamente 3.000 espécies distribuídas em 42 famílias (BARBER-JAMES et al. 2008). São encontradas em todas as regiões biogeográficas, exceto na Antártica, no extremo Ártico e em pequenas ilhas oceânicas (EDmunds et al. 1976).

Muitas espécies são conhecidas somente em um estágio, normalmente adulto ou ninfa, dependendo do gênero ou até mesmo da família em questão. Técnicas foram criadas para tentar obter melhores resultados no sentido do conhecimento taxonômico sobre a ordem, obtendo a associação entre ninfa, subimago e imago. Uma delas é a criação da ninfa em campo ou laboratório, onde a ninfa é colocada em recipientes plásticos e armazenada até a muda de ninfa para subimago. A subimago então é condicionada em recipiente fechado até a próxima muda e obtenção do adulto. Essa técnica é bem detalhada em EDMunds JR. et al. (1976).

Mas nem sempre é possível fazer a criação de ninfas em campo adequadamente, principalmente quando o pesquisador se encontra numa longa viajem de pesquisa. Dessa forma, quando as ninfas são retiradas da água e colocadas em caixas de isopor ou outro meio de transporte, essas ninfas acabam morrendo devido ao estresse causado pela grande movimentação da água durante o deslocamento do veículo.

Com a necessidade de obter melhores resultados na criação de ninfas em campo, nesse estudo propomos uma nova metodologia para criação e transporte de ninfas de Ephemeroptera.

O material para confecção da criação (modificada de EDMUNDS JR. et al. 1976) são, copo plástico, filó, elástico, copos de transporte tipo PET, cola quente e isopor. No copo plástico é cortado um circulo no fundo e com a cola quente fixa-se a malha ao fundo do copo (Figuras 1A e 1B), a milimetragem da malha depende do tamanho da ninfa a ser criada, evitando dessa forma fugas do recipiente de criação. Nesse estudo foi utilizado o copo com diâmetro superior de 7,7 cm e diâmetro inferior de 4,8 cm. O filó serve para cobrir a abertura superior, impedindo a fuga do inseto após a emersão.

As ninfas coletadas e que estão favoráveis para a criação, com a teca alar madura (Figura $1 \mathrm{C}$ ), são retiradas da água e inseridas individualmente nos copos plásticos que estão encaixados no material flutuante (EVA ou isopor) dentro do rio ou lagoa (Figura 1D), dependendo do local onde as ninfas foram coletadas (SAlles et al. 2012). É recomendável que as ninfas estejam no último instar ou próximo, já que neste instar os insetos não se alimentam, diminuindo cuidados e manutenção.

Havendo a necessidade de deslocamento, o copo de transporte é enchido com água na medida que o copo de criação (contendo as ninfas) ao ser inserido, fique com água suficiente para manter a ninfas submersas (Figura 1E), o que correspondeu neste trabalho a 3/4 de água. $O$ copo de criação utilizado neste estudo possui $7 \mathrm{~cm}$ de altura e $6 \mathrm{~cm}$ de diâmetro.

Com essa metodologia foi verificada menor agitação da água dentro do copo de criação, que é propiciada pelo formato circular do copo de transporte, fazendo com que qualquer impacto resulte em uma corrente de água somente no copo de transporte. Essa metodologia permite o transporte de ninfas vivas por longos caminhos, uma vez que as ninfas se agarram na tela do fundo do copo, sendo menos movimentas pela água e menos estressadas devido ao movimento causado pelo transporte.

Além da manutenção de um leve fluxo de água, as metodologias anteriores necessitam da adição de um substrato, normalmente galhos, para a fixação da ninfa. Contudo, esses substratos podem dificultar a emersão das ninfas esmagando a ninfa dentro do copo ou no caso da subimago, essa pode se chocar contra o substrato,

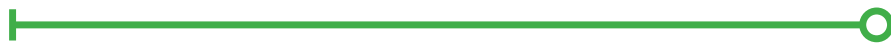

Agência(s) de Fomento: Programa de Capacitação em Taxonomia -MCT/CNPq/MEC/CAPES/PROTAX no 52/2010 (Processo número 140201/2011-4) 

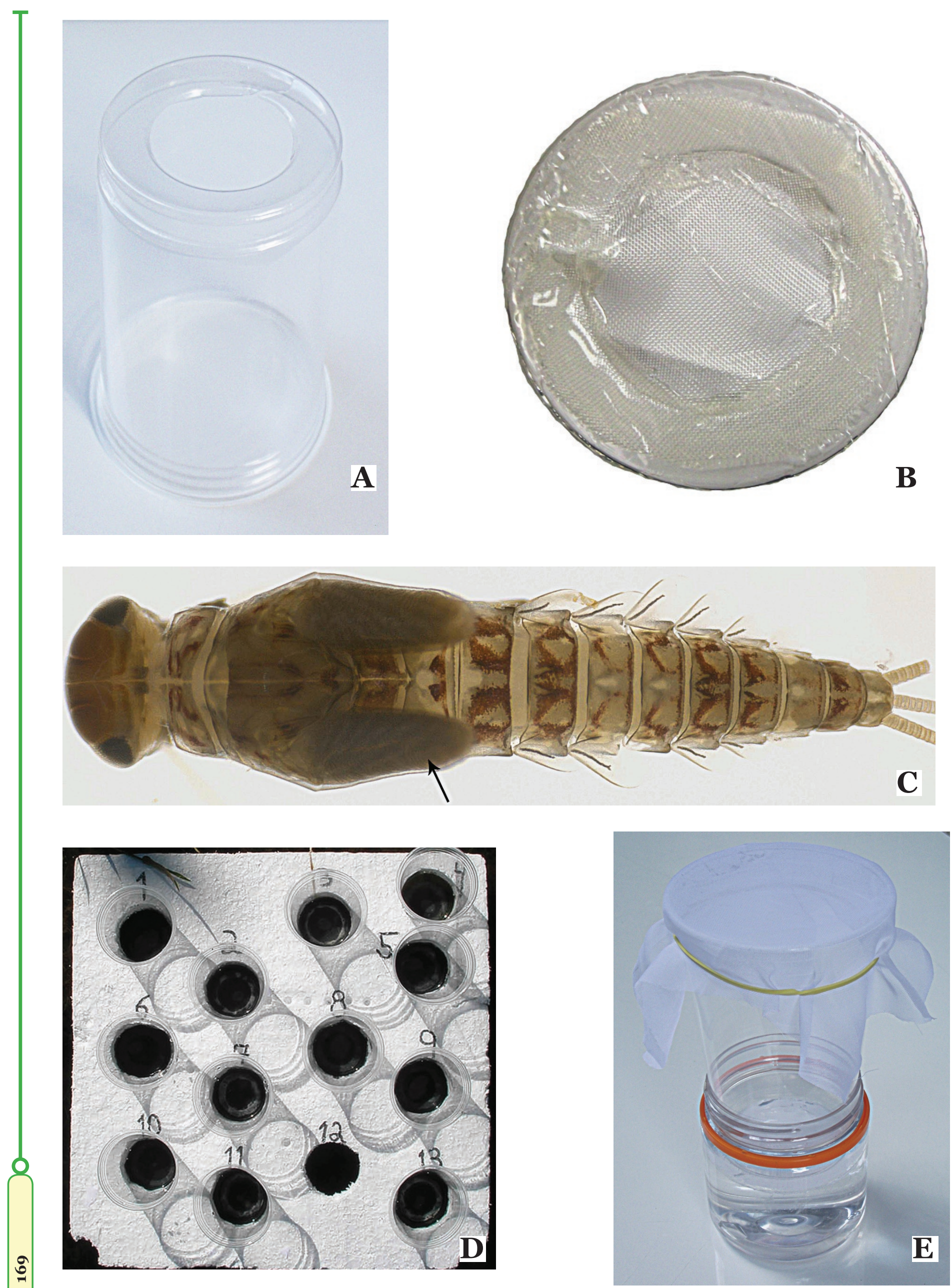

Figura 1. A. Copo de criação; B. Fundo do copo com malha; C. Ninfa com teca alar madura; D. Isopor com copos de criação. E. Aparato de transporte. 
sofrendo algum impacto que impeça que ela faça a próxima muda para adulto.

Com este método foi possível associar as ninfas e adultos de Callibaetis pollens Needhan \& Murphy, Callibaetis gonzalezi (Návas), Callibaetis fasciatus (Pictet), Camelobaetidius janae Dominique \& Thomas e Camelobaetidius yacutinga Nieto, Paracloeodes atroari Nieto \& Salles, Paracloeodes binodulus Lugo-Ortiz \& McCafferty, Paracloeodes ibicui LugoOrtiz \& McCafferty, Paracloeodes pacawara Nieto \& Salles, Paracloeodes peri Nieto \& Salles e Rivudiva trichobasis LugoOrtiz \& McCafferty. Pode-se observar que até mesmo ninfas que vivem em região com muita corredeira, no caso Camelobaetidius, e que normalmente morrem após serem retiradas da água, conseguiram sobreviver dentro do copo por até 2 dias. O período máximo de criação e emersão foi com a espécie $C$. gonzalezi, que sobreviveu pelo período de uma semana.

\section{AGRADECIMENTOS}

Os autores gostariam de agradecer a Dra. Neusa Hamada (Instituto Nacional de Pesquisas da Amazônia) pelo suporte logístico. PVC agradece ao financiamento do - Programa de Capacitação em Taxonomia -MCT/CNPq/MEC/CAPES/PROTAX n ${ }^{0}$ 52/2010 (Processo número 140201/2011-4)

\section{REFERÊNCIAS}

Barber-James, H.M., J.L. Gattolliat, M. Sartori \& M.D. Hubbard, 2008. Global diversity of mayflies (Ephemeroptera, Insecta) in freshwater. Hydrobiologia, 595: 339-350.

Edmunds Jr., G.F., S.L. Jensen \& L. Berner, 1976. The mayflies of North and Central America. Minneapolis, University of Minnesota Press, 338 pp.

Salles, F.F., R. Boldrini, J.M.C. Nascimento, E.A. Raimundi \& Y. Shimano, 2011. Ephemeroptera do Brasil. Disponível em $<$ http://sites.google.com/site.ephemeropterabr $>$. Acesso em 17/08/2012.

Recebido em: 24/o9/2012

Aceito em: 14/o3/2013

Como citar este artigo:

Boldrini, R. \& P.V. Cruz, 2013. Criação e Transporte de Ninfas de Ephemeroptera (Insecta) em Campo. EntomoBrasilis, 6(2): 168-170. Acessível em: http://www.periodico.ebras.bio.br/ojs/index.php/ebras/article/view/281. doi:10.12741/ebrasilis.v6i2.281

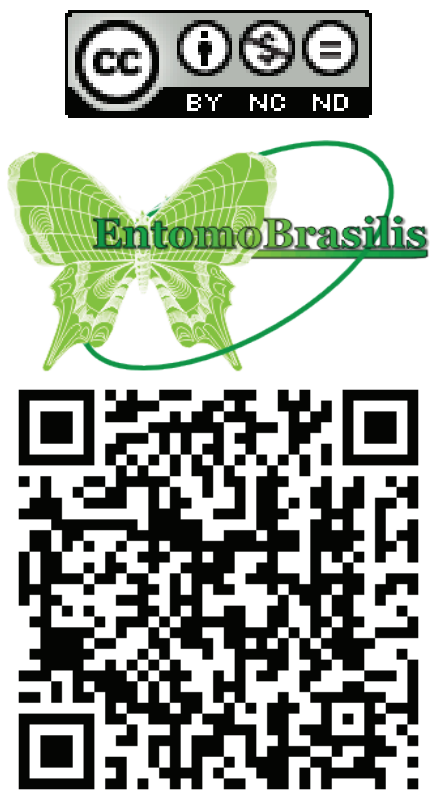

